\title{
Do conhecimento tácito ao conhecimento explícito: a elaboração de manual de política de indexação em bibliotecas universitárias
}

Del conocimiento tácito al explícito: elaboración de un manual de política de indización en bibliotecas universitarias

From tacit to explicit knowledge: elaborating an indexing policy handbook for university libraries

Milena Polsinelli RubI (1), Mariângela Spotti Lopes FuJITA (2), Vera Regina Casari Boccato (3)

(1) Universidade Federal de São Carlos, Campus de Sorocaba, Biblioteca, Rodovia João Leme dos Santos, Km 110 - SP-264, Bairro do Itinga, CEP 18052-780, Sorocaba, SP, Brasil, milenarubi@ufscar.br (2) Universidade Estadual Paulista Júlio de Mesquita Filho, campus de Marília, Departamento de Ciência de Informação, Av. Hygino Muzzi Filho, 737, Campus Universitário, CEP 17525-900, Marília, SP, Brasil, fujita@marilia.unesp.br (3) Universidade Federal de São Carlos, Campus de São Carlos, Departamento de Ciência de Informação, Rodovia Washington Luiz, Km 235, CEP 13565905, São Carlos, SP, Brasil, vboccato@ufscar.br.

\begin{abstract}
Resumen
La política de indización establece los princios y criteris que actúan como guía para el indizador en la determinación de los temas. En este artículo se muestra como capturar el conocimiento tácito del indizador pro medio de la metodología del protocolo verbal en grupo, y transformarlo en conocimiento explícito bajo la forma de un manual de indización. Se demuestra que a formación permanente del profesional indizador es fundamental para el desarrollo de la política de indización de su biblioteca.
\end{abstract}

Palabras clave: Política de indización. Manual de indización. Conocimiento organizacional. Formación permanente.

\section{Introdução}

A indexação diz respeito à identificação do conteúdo do documento, por meio do processo de análise de assunto, e à representação desse conteúdo através de conceitos. Esses conceitos serão representados em termos advindos de uma linguagem documentária, com vistas à intermediação entre o documento e o usuário no momento da recuperação da informação.

A importância da indexação, em um sistema de recuperação da informação, revela-se a partir da realização desse processo de intermediação, no qual os resultados da questão de busca do usuário estarão condicionados.

Responsável pela indexação e, portanto, igualmente importante é o indexador. Ele tem a função de realizar a análise conceitual que representará o conteúdo do documento para que ocorra a correspondência com 0 assunto pesquisado pelo usuário.

No entanto, o indexador está sujeito às condições específicas do seu trabalho: limite de tem-

\begin{abstract}
The indexing policy establishes the guiding principles and criteria for the indexer when determining the subjects of the documents. This article shows how to capture the indexers' tacit knowledge into explicit knowledge using the group verbal protocol methodology to produce an indexing manual. Continuing professional education results to be a key factor in obtaining good results when formalizing the indexing policy of a library and keeping it up to date.
\end{abstract}

Keywords: Indexing policy. Indexing manual. Organizational knowledge. Continuing education.

po, propósito definido, geração de produtos e serviços e grande volume de documentos de diferentes áreas de assunto (Farrow, 1991, Fujita, 1999; Cremmins, 1982).

O estabelecimento de uma política de indexação será norteadora de princípios e critérios que servirão de guia para tomada de decisões visando à otimização do serviço e à racionalização dos processos, servindo como subsídio para a organização do conhecimento no catálogo, atuando como guia para o indexador no momento da determinação dos assuntos dos documentos descritos nesses registros.

Além disso, a política de indexação deve estar descrita e registrada em manuais de indexação para que possam ser constantemente avaliadas e modificadas, se preciso. Nesse contexto, o conhecimento organizacional do indexador deverá ser o principal contribuidor para que o manual seja sempre atualizado e efetivado.

Com a proposta de analisar os aspectos teóricos sobre política de indexação, sob a perspectiva do conhecimento organizacional, o objetivo 
é demonstrar como a política de indexação pode ser elaborada a partir do conhecimento tácito do indexador produzido no contexto organizacional da biblioteca, por meio da metodologia do Protocolo Verbal em Grupo (PVG), transformando esse conhecimento em explícito na forma de manual de indexação.

\section{O conhecimento organizacional para elaboração de política de indexação}

A biblioteca é uma organização que agrega valor à informação ao adquiri-la e processá-la tecnicamente de forma a torná-la disponível.

Sob esse ponto de vista, Tamayo (1998), que trabalha com estudos sobre cultura organizacional, esclarece que existem duas abordagens principais que podem ser utilizadas no estudo dos valores organizacionais: a partir dos documentos oficiais da empresa e a partir de observações de como os valores são percebidos pelos empregados. No nosso caso, elementos de política de indexação são os valores peculiares de cada biblioteca que estão expressos oficialmente em manuais de indexação.

Esses valores existentes nos documentos oficiais foram observados por meio dos manuais de indexação, documentos oficiais das bibliotecas, nos quais estão descritos formalmente os elementos de política de indexação (Rubi e Fujita, 2003).

Enveredando ainda pela área da Administração, encontramos também os estudos a respeito do conhecimento tácito e do conhecimento explícito, objetos de estudos da gestão do conhecimento e que, por definição, atende aos nossos interesses.

Nonaka e Takeuchi (1997, p. 65) explicam que a criação do conhecimento organizacional deve ser entendida como um processo que amplia "organizacionalmente" o conhecimento criado pelos indivíduos, cristalizando-o como parte da rede de conhecimento da organização.

Utilizando definições estabelecidas por Michael Polanyi (1966), Nonaka e Takeuchi (1997, p. 65) distinguem dois tipos de conhecimentos complementares: conhecimento tácito e conhecimento explícito.

O conhecimento tácito é pessoal, específico ao contexto e, assim, difícil de ser formulado e comunicado. O conhecimento explícito refere-se ao conhecimento transmissível em linguagem formal e sistemática. (Nonaka e Takeuchi, 1997, p. 65).

Convém ressaltar aqui o alerta que os autores fazem sobre a necessidade da verbalização e da diagramação do conhecimento sob a forma de documentos, manuais ou histórias orais para que o conhecimento explícito se torne tácito, para que a documentação ajude os indivíduos a internalizarem suas experiências, aumentando seu conhecimento tácito, e para facilitar a transferência do conhecimento explícito para as outras pessoas, ajudando-as a vivenciar a experiência dos outros.

Sobre isso, Nonaka e Takeuchi (1997, p. 83) explicam que

a função da organização no processo de criação do conhecimento é fornecer contexto apropriado para facilitação das atividades em grupo e para a criação e acúmulo de conhecimento em nível individual.

Portanto, pode-se afirmar que o conhecimento explícito dentro de uma biblioteca é composto por sua documentação oficial e que, especificamente no caso do serviço de indexação, por seu manual de indexação. Já o conhecimento tácito é aquele inerente a cada indivíduo que atua na biblioteca, como o gerente e o próprio indexador.

Dessa forma, os manuais de indexação têm como finalidade uniformizar os procedimentos de indexação realizados pelos indexadores. Sob esse ponto de vista, e nos apropriando das razões apontadas por Chinelato Filho (1997), que justificam a elaboração de um manual, pode-se afirmar, então, que um manual de indexação em uma biblioteca é importante devido: à missão da biblioteca que é disponibilizar a informação existente em seu acervo por meio do catálogo; à complexidade da tarefa de indexação e à necessidade de uniformização dos procedimentos por parte de indexadores de uma mesma biblioteca; ao registro dos procedimentos adotados para que, em caso de novo funcionário, a indexação possa continuar sendo realizada da mesma maneira.

O manual de indexação é uma documentação oficial, está descrito em ordem lógica de etapas a serem seguidas para a análise de assuntos, fornece as regras, diretrizes e procedimentos para o trabalho do indexador e, principalmente, contém os elementos constituintes da política de indexação adotada por um sistema de informação. Portanto, o manual de indexação é um dos meios pelo qual a política de indexação de uma biblioteca poderá ser observada.

Dessa maneira, consideramos que um manual de indexação deve ser uma condensação de três tipos: a) manual de operação ou procedimentos: pois ele deve descrever a atividade de indexação, dar instruções sobre a realização dessa tarefa e proporcionar métodos que possi- 
bilitem sua execução de maneira uniforme; b) manual de política: o manual deve descrever, de maneira geral e filosófica, as políticas a serem seguidas pelos indexadores no momento da indexação, coordenando, assim, esforços de todos os bibliotecários para que o objetivo da biblioteca seja alcançado; e c) manual de organização: deve servir como um repositório das experiências acumuladas dos indexadores mais antigos, a serem aproveitadas para facilitar o treinamento dos mais novos, podendo, com isso, constituir-se num manual de consultas.

Conforme a maneira como os manuais de indexação vêm se apresentando, pode-se afirmar que eles contemplam somente a combinação entre os dois primeiros tipos de manuais: de operação e de política. E é justamente no manual da organização que o conhecimento tácito do indexador deverá se tornar explícito, criando assim novos conhecimentos dentro do sistema de informação e servindo como instrumento de trabalho do indexador e fonte de informação para treinamento de novos profissionais.

Consideramos que a política de indexação é pertinente não somente aos objetivos específi$\cos$ da indexação, como também às decisões administrativas que devem refletir a filosofia da biblioteca em questão.

Porém, de maneira geral, a literatura sobre política de indexação se mostra escassa. No âmbito nacional, destaca-se o clássico artigo de Carneiro (1985). Para a referida autora, os seguintes elementos devem ser considerados na elaboração de uma política de indexação: Cobertura de assuntos; Seleção e aquisição dos documentos-fonte; Processo de indexação (Nível de exaustividade; Nível de especificidade; Escolha da linguagem; Capacidade de revocação e precisão do sistema); Estratégia de busca; Tempo de resposta do sistema; Forma de saída; Avaliação do sistema.

Em âmbito internacional, podemos destacar o trabalho do espanhol Cubillo (2000) que alerta sobre a importância e a urgência da implantação de política de indexação.

Para Foskett (1973), três aspectos devem ser complementares ao estudo sobre política de indexação. São eles: capacidade de consulta a esmo; garantia literária; formação do indexador.

Olson e Boll (2001) afirmam que, no processo de indexação, as chances de uma melhor correspondência entre a indexação e a questão de busca do usuário dependem de fatores como adequação, exaustividade, especificidade e consistência.
As definições sobre especificidade e exaustividade e as implicações desses elementos no processo de indexação remetem aos princípios básicos elaborados por Charles Ammi Cutter dentro do conjunto de regras para construção e arranjo de cabeçalhos de assunto: do uso, da entrada específica e da estrutura sindética.

Nesse sentido, acreditamos que os princípios de Cutter e as Leis de Ranganathan podem ser considerados como indícios primários de uma política de indexação, uma vez que se referiam: ao modo como deveriam ser as entradas dos assuntos pelos termos determinados (princípio da entrada específica); à indicação das relações associativas, de equivalência e hierárquicas entre os termos (princípio da estrutura sindética); sobre a necessidade dos usuários no momento da descrição dos assuntos (princípio do uso).

Além dos elementos de política de indexação já conhecidos e divulgados na literatura, o artigo de Moen e Benardino (2003) nos chama a atenção quando apresenta um interessante estudo relacionando a política de indexação com o MAchine Readable Cataloging (MARC), formato utilizado para descrição bibliográfica que possibilita não só a automação das bibliotecas, como o intercâmbio de registros bibliográficos legíveis por máquina. Os autores esclarecem que a política de indexação deve também delinear quais os campos e sub/campos do formato MARC que são efetivamente utilizados na construção do catálogo e na recuperação da informação.

Vílchez Pardo (2002) apresenta uma publicação espanhola, intitulada Lista de encabezamiento de materia para bibliotecas públicas, em que são apresentados princípios para determinação de cabeçalhos de assunto. São eles:

- Especificidade: O cabeçalho designa um único assunto.

- Síntese: O conteúdo expresso com a maior simplicidade possível.

- Uso: Não perder de vista o usuário, a coleção etc.

- Linguístico: Linguagem acessível e na ordem normal do idioma.

- Uniformidade: Para cada assunto haverá um cabeçalho uniforme, destacar os casos de homonímia.

- Economia: Não determinar vários cabeçalhos de assunto a um único documento. Em caso de biblioteca pública, determinar um assunto mais geral. 
Todos esses elementos deverão estar contemplados em um manual de indexação, juntamente com os aspectos referentes ao processo de indexação, à filosofia da biblioteca e ao conhecimento organizacional em que esse manual será utilizado.

Porém, como ter acesso ao conhecimento tácito do indexador?

Lembrando o que os autores Nonaka e Takeuchi (1997) afirmaram sobre a função da organização no processo de criação do conhecimento, que é fornecer contexto apropriado para facilitação das atividades em grupo e para a criação e acúmulo de conhecimento em nível individual, apresentamos a seguir os resultados de estudo realizado (Rubi, 2008), os quais utilizamos para investigação do conhecimento tácito dos indexadores que é uma abordagem metodológica, a qual consideramos adequada para esse fim: protocolo verbal em grupo.

\section{Metodologia}

De acordo com Nardi (1999), a origem do protocolo verbal em grupo está na metodologia introspectiva do protocolo verbal nos moldes de Ericsson e Simon (1987), um instrumento de coleta de dados introspectivos, originalmente utilizado para coletar informações sobre processos mentais utilizados pelos indivíduos na realização de qualquer tipo de tarefa.

O protocolo verbal em grupo consiste na reunião de pessoas (sujeitos participantes e pesquisador) para a leitura de um texto e discussão de temas suscitados pelo mesmo. Nesse caso, o pesquisador interage como um dos sujeitos participantes com uma única função a mais, controlar o gravador.

O referido estudo (Rubi, 2008) foi realizado em uma amostra de 9 bibliotecas da Universidade Estadual Paulista (Unesp) das três áreas do conhecimento - Humanas, Exatas e Biológicas - respectivamente, Pedagogia, Engenharia Civil e Odontologia. Foi realizado protocolo verbal em grupo com bibliotecários chefes, bibliotecários catalogadores, bibliotecários de referência, usuários docentes pesquisadores, líderes de grupos de pesquisa, e usuários discentes de graduação e pós-graduação para acesso ao conhecimento das pessoas que participam do contexto de tratamento de conteúdos documentários de bibliotecas universitárias como fonte de coleta de dados qualificada sobre os elementos que compõem a política de indexação.

O protocolo verbal em grupo prescinde dos seguintes procedimentos:
3.1. Procedimentos anteriores à coleta de dados

- Definição do universo da pesquisa: Bibliotecas universitárias da Rede de Bibliotecas Unesp;

- Seleção do texto-base: Trecho entre as páginas 205 e 208 do seguinte artigo: Dias, E. W.; Naves, M. M. L.; Moura, M. A. (2001). O usuário-pesquisador e a análise de assunto. // Perspectivas em Ciência da Informação. 6:2 (Jul./Dez. 2011) 205 - 221.

- Definição da tarefa: Discussão do texto-base previamente referenciado.

- Seleção dos sujeitos: População de bibliotecários catalogadores representativa das três áreas do conhecimento - Humanas, Exatas e Biológicas - respectivamente, Letras, Matemática e Odontologia em nove bibliotecas da UNESP.

- Conversa informal com os sujeitos: Nesta conversa, as pesquisadoras fizeram contato com os sujeitos por intermédio da Coordenadoria Geral de Bibliotecas explicando os objetivos da pesquisa, a metodologia utilizada e agendando o dia para a coleta de dados. Todos os participantes tiveram suas identidades preservadas.

\subsection{Procedimentos durante a coleta de dados}

- Após a leitura do texto-base, iniciou-se a discussão, em que o pesquisador fez as intervenções necessárias de modo a instigar os participantes. Toda a discussão foi gravada e transcrita na íntegra.

\subsection{Procedimentos posteriores à coleta de dados}

- Transcrição das gravações: Após a gravação da discussão do texto pelos sujeitos, foi feita a transcrição literal com a identificação das fontes das falas individuais. Essa identificação foi feita da seguinte forma: BibliotecárioChefe; Bibliotecário de Referência; Bibliotecário Catalogador; Docente; Aluno; Pesquisador.

- Análise das transcrições: Com a transcrição pronta, foi feita uma leitura detalhada dos dados em busca de fenômenos significativos e recorrentes para construir categorias de análise que permitissem a análise dos dados de forma organizada e eficiente. Posteriormente à construção das categorias, voltou-se aos dados novamente para retirar trechos da transcrição que exemplifiquem cada categoria. 


\section{Resultados e discussão}

As categorias de análise foram elaboradas a partir dos elementos de política de indexação identificados no referencial teórico sobre o tema. São elas: capacidade de revocação e precisão; especificidade; exaustividade; formação do indexador; procedimentos relacionados à indexação; manual de indexação (elaboração/utilização); escolha da linguagem; consistência/uniformidade; adequação; avaliação; campos de assunto do formato MARC; Capacidade de consulta a esmo (browsing); estratégia de busca; forma de saída dos dados. Os resultados demonstraram a visão dos indexadores sobre o contexto em que a política de indexação está inserida e, para melhor visualização, foram divididos de acordo com as categorias que foram estabelecidas para análise dos dados.

\subsection{Capacidade de revocação e precisão}

A alta revocação está ligada à baixa precisão dos termos designados para representar seus assuntos. Acreditamos que a biblioteca deva adotar o detalhamento e a exaustividade também para o tratamento temático de seus livros. Essa decisão política resultará em uma recuperação com níveis de revocação menor e com um índice maior de precisão, ou seja, mesmo sendo um número reduzido de documentos, são exatamente esses que correspondem às questões de busca do usuário. Além disso, consideramos que deva haver um equilíbrio entre $o$ número de assuntos determinados e a especificidade desejada.

\subsection{Especificidade}

Um dos critérios para determinação do nível de especificidade dos assuntos dos documentos é a biblioteca onde esses documentos estão inseridos. A tendência geral entre as bibliotecas é representar o assunto dos documentos no nível mais geral, fazendo com que haja uma alta revocação, ou seja, a recuperação de um grande número de documentos. A decisão política que envolve a questão da especificidade está muito ligada à questão da revocação e precisão, que vimos na categoria anterior, e com a exaustividade, que veremos a seguir. Todas elas devem ser pensadas conjuntamente de modo a definir o perfil do catálogo da biblioteca, se ele será mais específico, garantindo uma maior precisão na recuperação, ou se ele será mais exaustivo aumentando a revocação do sistema.

\subsection{Exaustividade}

Não há uma decisão política sobre o número de termos designados para representar o assunto do documento. O limite é determinado pelo bibliotecário no momento da catalogação e dependerá dos assuntos abordados no documento e na sua comunidade usuária. Para evitar disparidades entre os bibliotecários e as bibliotecas, é necessária a elaboração de um manual de indexação que contemple todos os aspectos citados anteriormente e determine como eles serão trabalhados por todos da rede de bibliotecas.

\subsection{Formação do indexador}

Há uma preocupação da CGB em capacitar os catalogadores quanto à utilização do padrão Unesp para a catalogação. Não há um curso específico voltado para o processo de indexação, cuja aprendizagem é feita na prática do dia a dia durante o fazer bibliotecário com iniciativa do próprio profissional e com auxílio de especialistas nas áreas de assunto. Acreditamos que a mesma atenção dada ao tratamento descritivo, por meio de formação continuada e o desenvolvimento de um manual que contém os padrões a serem seguidos nesse tipo de representação, deva ser dispensada também ao tratamento temático dos documentos.

\subsection{Procedimentos relacionados à indexação}

O bibliotecário segue o padrão da Unesp para catalogação, porém não há nada específico a respeito do procedimento de leitura documentária para determinação do termo. A política de indexação deve indicar e detalhar todos os procedimentos que devem ser realizados durante o processo de indexação, quais sejam: análise, síntese e representação. A descrição dos procedimentos permitirá que um padrão mínimo seja seguido por todas as bibliotecas da Rede, auxiliando os bibliotecários e atuando também como um instrumento de formação em serviço.

\subsection{Manual de indexação (elaboração/utilização)}

Não há nenhuma iniciativa concreta em relação à elaboração de manuais de indexação. Os manuais utilizados são aqueles de serviço (como regimentos e regulamentos) e o padrão Unesp para catalogação, porém nenhum deles apresenta ao menos diretrizes sobre a representação de assunto. Deve ser uma decisão da Unesp, enquanto rede, elaborar um manual que contemple também a questão do tratamento temático da informação, no que diz respeito aos seus procedimentos, a sua filosofia e suas diretrizes, que possa guiar o bibliotecário durante seu serviço. 


\subsection{Escolha da linguagem}

Observamos que a linguagem documentária não atende às necessidades específicas da demanda da comunidade usuária, dificultando também o trabalho do bibliotecário. A decisão política sobre a escolha da linguagem deve levar em conta questões sobre sua manutenção, atualização, pertinência e especificidade de forma a atender adequadamente os usuários da biblioteca.

\subsection{Consistência/uniformidade}

Há uma preocupação dos bibliotecários quanto à padronização dos termos utilizados para os mesmos documentos das mesmas áreas, caracterizando a Rede de Bibliotecas como tal. A política de indexação pode definir qual o nível de especificidade sobre o qual um documento será representado, tendo em vista, principalmente, os cursos atendidos pela biblioteca.

\subsection{Adequação}

Existe esforço do bibliotecário no que diz respeito à representação exata do conteúdo do documento. A decisão sobre qual linguagem utilizar e em qual momento diminuiria as incoerências cometidas durante esse processo no que diz respeito à representação adequada do assunto do documento.

\subsection{Avaliação}

A ausência de um sistema de remissivas que remeta o usuário, no momento da busca, para a linguagem utilizada pelo sistema faz com que haja certo "saudosismo" em relação às fichas catalográficas em papel. A utilização de um software para recuperação da informação em um catálogo on-line deve ser preocupação da política de indexação nas questões relativas à interface de busca que permita a organização da informação e a interatividade entre o usuário.

\subsection{Campos de assunto do formato MARC}

Mesmo havendo um campo (690) que deveria contemplar o termo utilizado pelo usuário que não está na linguagem, ou seja, livre, duas bibliotecas da área de Odontologia adotaram como decisão política o controle também desse campo, utilizando uma linguagem documentária mais específica da área de saúde e que atende de forma mais adequada sua comunidade usuária. Uma decisão política poderia apresentar diretrizes gerais para a padronização e controle do campo 690, que poderia levar em consideração a utilização de uma linguagem documentária auxiliar específica de uma determinada área.
4.12. Capacidade de consulta a esmo (browsing)

Há uma insatisfação por parte do usuário e do bibliotecário quanto à organização da informação que reflete no momento da recuperação da informação. Uma decisão política seria permitir a visualização da linguagem documentária adotada pelo sistema de recuperação da informação pelo usuário no momento da busca.

\subsection{Estratégia de busca}

O tipo de busca mais realizada é por assunto, porém é aquela que mais traz dificuldade ao usuário. Quando isso ocorre, o usuário recorre ao bibliotecário para que o auxilie no uso das bases de dados, refinamento do assunto e tradução desse assunto nos termos de busca. Uma forma de auxiliar o usuário (e o bibliotecário) no momento da recuperação da informação é a disponibilização da linguagem para que o usuário faça a consulta, verifique as opções do sistema de recuperação da informação e decida pelo termo que melhor represente sua necessidade de busca.

\subsection{Forma de saída dos dados}

Inicialmente, os catálogos automatizados coexistindo com os catálogos em fichas causavam resistência dos usuários quanto a sua utilização. Porém, a facilidade e a rapidez na recuperação da informação fizeram com que os usuários valorizassem as buscas pelo catálogo on-line. Para melhoria na recepção dos resultados de busca, apresentou-se como sugestão a separação dos itens bibliográficos de acordo com sua tipologia.

Esses resultados só foram possíveis devido à utilização da metodologia do protocolo verbal que permitiu a verificação do contexto de trabaIho dos bibliotecários, da visão dos bibliotecários e usuários a respeito da política de indexação e dos procedimentos adotados durante a determinação dos assuntos dos documentos pelos bibliotecários. Além disso, permitiu que tivéssemos acesso ao dia a dia do fazer bibliotecário, bem como sua relação com seu contexto de trabalho e com os usuários e que conhecêssemos a linguagem utilizada pelos bibliotecários durante a realização de sua tarefa, em que ficou evidente a distância entre a teoria biblioteconômica e o fazer bibliotecário.

\section{Considerações finais}

Consideramos ser necessário que as bibliotecas percebam a importância da indexação em todo o ciclo documentário, considerando-a como 
parte da administração, compreendendo que esse processo necessita de parâmetros que guiem os indexadores no momento de tomadas de decisões, minimizando subjetividade e incertezas durante o processo de indexação, reconhecendo, portanto, a importância de se implantar uma política de indexação.

Observamos que identificar e compartilhar conhecimento explícito não são tarefas difíceis, pois este conhecimento é claro e estruturado podendo ser representado facilmente por meio de procedimentos, linguagem, documentos, bancos de dados, etc. A maior dificuldade está na identificação e compartilhamento do conhecimento tácito, o que exige um intenso contato pessoal, pois refere-se ao conhecimento subjetivo, às experiências, habilidades e intuições acumuladas pelo indivíduo ao longo de sua vida.

Sobre a política de indexação, observamos que ela deve ser compreendida como uma decisão administrativa, representada por meio de uma filosofia que reflita os objetivos da biblioteca, identificando condutas teóricas e práticas do indexador envolvido no processo de indexação para o catálogo da biblioteca para definir um padrão de cultura organizacional coerente com a demanda da comunidade acadêmica interna e externa.

Essa metodologia, enquanto abordagem metodológica sociocognitiva, tem como foco o sujeito que realiza uma determinada atividade e sua cognição em relação ao seu contexto de produção. O foco está no contexto de tratamento temático do bibliotecário catalogador constituído de objetivos da indexação, política de indexação, regras e procedimentos do manual de indexação, a linguagem para representação e mediação da linguagem do usuário e os interesses de busca do usuário.

Acreditamos que o maior investimento da biblioteca deva ser empregado na formação continuada do profissional indexador para que seu conhecimento seja sempre atualizado e para que ele se torne fonte de conhecimento sobre a política e a indexação da biblioteca.

Assim o manual de indexação deve ser elaborado pelas seguintes razões: complexidade da tarefa de indexação e a necessidade de uniformização de seus procedimentos; registro dos procedimentos adotados para que, em caso de novo funcionário, a indexação possa continuar sendo realizada da mesma maneira.

Dessa forma, o manual de indexação deverá funcionar como repositório do conhecimento tácito do indexador e fonte do conhecimento explícito para o indexador, servindo como ferramenta útil ao processo de indexação.

\section{Referências}

Carneiro, M. V. (1985). Diretrizes para uma política de indexação. // Revista da Escola de Biblioteconomia da UFMG. 14:2 (Setembro 1985) 221-241.

Chinelato Filho, J. (1997). O \& M integrado à informática. 7. ed. Rio de Janeiro: LTC, 1997.

Cremmins, E. T. (1982). The art of abstracting. Philadelphia: ISI Press, 1982.

Cubillo, J.(200). Cambio y continuidad en las organizaciones de gestión del conocimiento. // DataGramaZero: Revista de Ciência da Informação. 1:4 (Agosto 2000).

Cutter, C. A. (1876). Rules for a printed dictionary catalogue. Washington, D.C.: Government Printing Office, 1876.

Ericsson, K. A.; Simon, H. A. (1987). Verbal reports on thinking. // Faerch, C.; Kasper, G. (eds.). Introspection in second language research. Clevedon: Multilingual Matters Ltd., 1987. 24-54.

Farrow, J. F. (1991). A cognitive process model of document indexing. // Journal of documentation. 47:2 (1991) 149-166.

Foskett, A. C. (1973). A abordagem temática da informação. São Paulo: Polígono; Brasília: UnB, 1973.

Fujita, M. S. L. (1999). A leitura do indexador: estudo de observação. // Perspectivas em Ciência da Informação, 4:1 (jan./jun. 1999) 101-116.

Moen, W. E; Benardino, P. (2003). Assessing metadata utilization: an analysis of MARC content designation use. // Proceedings of Dublin Core Conference: Supporting Communities Of Discourse And Practice - Metadata Research And Application. 2003, Seattle. Seattle: Information School of the University of Washington, 2003.

Nardi, M. I. A. (1999). A metáfora e a prática de leitura como evento social: instrumentos do pensar a Biblioteconomia do futuro. São Paulo: Universidade Católica, 1999. 272 f. Tese (Doutorado em Linguística Aplicada e Estudos da Linguagem Pontifícia).

Nonaka, I.; Takeuchi, H. (1997). Teoria da criação do conhecimento organizacional. // Nonaka, I.; Takeuchi, H. (Eds.) Criação de conhecimento na empresa: como as empresas japonesas geram a dinâmica da inovação. Rio de Janeiro: Campus, 1997. 61-102.

Olson, H. A.; BolL, J. (2001). Subject analysis in online catalogs. 2. ed. Englewood, CO: Libraries Unlimited, 2001.

Polanyi, M. (1966). The tacit dimension. Garden City, N.Y.: Doubleday \& Co., 1966.

Rubi, M. P. (2008). Política de indexação para construção de catálogos cooperativos em bibliotecas universitárias. Marília, Universidade Estadual Paulista: Faculdade de Filosofia e Ciências, 2008. 176 f. Tese (Doutorado em Ciência da Informação).

Rubi, M. P.; Fujita, M. S. L.(2003). Elementos de política de indexação em manuais de indexação de sistemas de informação especializados. // Perspectivas em Ciência da Informação. 8:1 (Janeiro/Junho 2003) 66-77.

Tamayo, A. (1998). Valores organizacionais: sua relação com satisfação no trabalho, cidadania organizacional e comprometimento afetivo. // Revista de Administração. 4 (Julho/Setembro 1998) 56-63.

Vílchez Pardo, J. (2002). Tratamiento y ubicación de la colección. // Orera Orera, L. (eds.). Manual de Biblioteconomía. Madrid: Síntesis, 2002. 113-136.

Enviado: 2012-04-14. Versión corregida: 2012-08-21. Aceptado: 2012-08-21. 
